\title{
Transcriptomic analysis and validation reveal the pathogenesis and a novel biomarker of acute exacerbation of chronic obstructive pulmonary disease
}

\author{
Huijie Wang ${ }^{1,2 \dagger}$, Yonghong Zhong ${ }^{3 \dagger}, \mathrm{Na} \mathrm{Li}^{1+}$, Min Yu${ }^{3}$, Lin Zhu' ${ }^{1}$, Lina Wang ${ }^{1}$, Fei Chen ${ }^{1}$, Yaping Xu ${ }^{1,4}$,
} Jian Liu ${ }^{1,4}$ and Huaqiong Huang ${ }^{1 *}$ (i)

\begin{abstract}
Background: Acute exacerbation of chronic obstructive pulmonary disease (AECOPD) is the main factor that leads to the deterioration of the disease. Currently, the diagnosis of AECOPD mainly relies on clinical manifestations, good predictors or biomarkers are lacking. We aim to reveal specific biomarkers and potential pathogenesis of AECOPD and provide a research basis for the diagnosis and treatment.
\end{abstract}

Methods: Four patients with AECOPD, four patients with stable COPD, and five control subjects were enrolled for RNA sequencing and KEGG analysis. The mRNA level of target genes was verified by quantitative real-time PCR (qPCR) with an expanded sample size (30 patients with AECOPD, 27 patients with stable COPD, and 35 control subjects). ELISA and immunofluorescence were used to identify the target proteins. Furthermore, the expression and function of WNT/ß-catenin signaling pathway were assessed in animal models of COPD.

Results: RNA sequencing showed that 54 genes were up-regulated and 111 genes were down-regulated in the AECOPD. Differentially expressed genes were mainly enriched in WNT signaling pathway, et al. QPCR revealed that multi-genes of the WNT/ $\beta$-catenin signaling were significantly down-regulated in AECOPD $(P<0.05)$, and $\beta$-catenin protein was significantly decreased in plasma of AECOPD and stable COPD $(P<0.01)$, while phosphorylated $\beta$-catenin was significantly up-regulated in peripheral blood mononuclear cells of AECOPD $(P<0.05)$. Similarly, WNT ligands, WNT receptors, and downstream signaling molecules were down-regulated, with an increased phosphorylated $\beta$-catenin protein in animal models of COPD. Activation of WNT/ $\beta$-catenin signaling pathway by lithium chloride reduced the expression of phosphorylated $\beta$-catenin and ameliorated the COPD-like airway inflammation in mice.

Conclusion: WNT/ $\beta$-catenin signaling pathway is down-regulated in AECOPD patients and in animal models of COPD. Increased expression of phosphorylated $\beta$-catenin in the blood might be a potential biomarker of AECOPD. Activation of WNT/ $\beta$-catenin pathway may also represent a therapeutic target for AECOPD.

\footnotetext{
*Correspondence: zr_hhq@zju.edu.cn

${ }^{\dagger}$ Huijie Wang, Yonghong Zhong and Na Li contributed equally to this manuscript

${ }^{1}$ Key Laboratory of Respiratory Disease of Zhejiang Province, Department of Respiratory and Critical Care Medicine, Second Affiliated Hospital of Zhejiang University School of Medicine, Hangzhou 310009, Zhejiang, China
}

Full list of author information is available at the end of the article

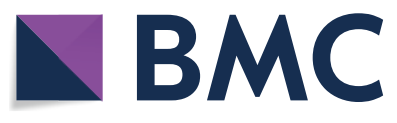

(c) The Author(s) 2022. Open Access This article is licensed under a Creative Commons Attribution 4.0 International License, which permits use, sharing, adaptation, distribution and reproduction in any medium or format, as long as you give appropriate credit to the original author(s) and the source, provide a link to the Creative Commons licence, and indicate if changes were made. The images or other third party material in this article are included in the article's Creative Commons licence, unless indicated otherwise in a credit line to the material. If material is not included in the article's Creative Commons licence and your intended use is not permitted by statutory regulation or exceeds the permitted use, you will need to obtain permission directly from the copyright holder. To view a copy of this licence, visit http://creativecommons.org/licenses/by/4.0/. The Creative Commons Public Domain Dedication waiver (http://creativecommons.org/publicdomain/zero/1.0/) applies to the data made available in this article, unless otherwise stated in a credit line to the data. 
Keywords: Chronic obstructive pulmonary disease, Acute exacerbation, Transcriptomic, Pathogenesis, Biomarkers

\section{Introduction}

Chronic obstructive pulmonary disease (COPD), characterized by persistent respiratory symptoms and restricted airflow, is a chronic airway disease that seriously endangers human health [1]. With continuous exposure to cigarette smoke and environmental pollutants, as well as the aging population, COPD has become the third leading cause of death in the world, with a global prevalence rate of $10.1 \%$ [2]. In China, the overall prevalence of COPD in people over 20 years old is $8.6 \%$, in people over 40 years old, a higher prevalence of COPD was 13.7\% [3].

Acute exacerbation of chronic obstructive pulmonary disease (AECOPD) is defined as patients who have acute exacerbation of respiratory symptoms and require additional treatment [1]. Frequent acute exacerbation will accelerate the deterioration of lung function and increase the social and economic burden. Predicting and identifying AECOPD is an important part of COPD management. Clinically, the diagnosis of AECOPD mainly depends on medical history and clinical manifestations. In recent years, the biomarkers of COPD have been an appealing direction of research, to find a convenient method for early monitoring, auxiliary diagnosis, and evaluation of treatment response.

Transcriptomics can simultaneously detect thousands of RNA and has gradually become an important tool for biomarker research. RNA sequencing (RNA-seq) is a transcriptomic analysis method using deep sequencing technology, which can detect the overall transcription activity of cells or tissues more accurately, efficiently, and widely [4]. Currently, a variety of RNA and molecular signaling pathways related to COPD were identified by transcriptomic, but the results of different studies are not highly repetitive. It is very important to verify the results of omics in multiple levels for finding reliable signaling pathways and biomarkers.

In this study, we performed RNA-seq of mRNA in peripheral blood mononuclear cells (PBMC) of patients with AECOPD, stable COPD, and control subjects, screened differentially expressed genes (DEGs) and multiple signaling pathways that potentially related to the pathogenesis of AECOPD by KEGG analysis. We use quantitative real-time PCR (qPCR) to verify the transcription level of $\mathrm{WNT} / \beta$-catenin signaling in an expanded-sample size, use ELISA and immunofluorescence to verify the differential expression of target genes at the protein level. Besides, we further elucidated the expression of $\mathrm{WNT} / \beta$-catenin signaling pathway in a traditional COPD model with cigarette smoke (CS) exposure, and in a novel COPD model combining cigarette smoke sensitization and elastin challenge $(\mathrm{CE})$.

\section{Methods \\ Patient population}

Patients with stable COPD and AECOPD and control subjects were recruited from the Second Affiliated Hospital of Zhejiang University School of Medicine, Hangzhou, China. All participants have given written informed consent to participate in the study, which was approved by the Institutional Review Board for Human Studies of Second Affiliated Hospital of Zhejiang University School of Medicine (Hangzhou, China). The definition of patients with stable COPD and AECOPD was according to the Global Initiative for Chronic Obstructive Lung Disease (GOLD 2018) [5]. Patients with stable COPD were enrolled based on the following criteria: (1) Over 40 years old. (2) In line with the diagnostic criteria in GOLD 2018. (3) With the ability to sign informed consent. (4) Can be followed up according to the study protocol. Exclusion criteria: (1) with other pulmonary diseases (such as lung cancer, sarcoidosis, tuberculosis, pulmonary fibrosis, cystic fibrosis) and severe $\alpha 1$-antitrypsin deficiency. (2) With other inflammatory diseases (such as rheumatoid arthritis and inflammatory bowel disease, etc.). (3) A history of pulmonary surgery, or a diagnosis of malignant tumor recently. (4) A history of blood transfusion in 4 weeks. (5) Participating in a double-blind drug clinical trial. (6) Unable to walk. (7) Using oral or intravenous steroid therapy. (8) With acute exacerbation in 4 weeks. For AECOPD, patients who were over 40 years old were eligible for inclusion if they had a diagnosis of COPD in their primary care clinical record and were presenting with an acute exacerbation of respiratory symptoms. Other specific diseases that may account for sudden changes in respiratory symptoms should be excluded by clinical or laboratory tests. The remaining exclusion criteria were consistent with the above five criteria in stable COPD. The control group included healthy people over 40 years old, excluding those with respiratory symptoms, chronic airway diseases, and other lung diseases, as well as heart, liver, kidney, and other important organ diseases.

\section{Animal models of COPD}

Six to 8 weeks male C57BL/6 mice were purchased from the Animal Centre of Slaccas (Shanghai, China). All mice were maintained in the animal facility of the laboratory animal center of Zhejiang University. Mice at the end of 
modeling were anesthetized by intraperitoneal injection of $0.2 \mathrm{~mL} 2 \%$ pentobarbital sodium and were killed by cervical dislocation, in the scientific research building of Zhejiang University. All experimental protocols were approved by the Ethical Committee for Animal Studies at Zhejiang University.

CE model: Mice $(n=5)$ were exposed to CS in a stainless-steel chamber using a whole-body smoke exposure system (TE-10, Teague Enterprises, Woodland, CA, USA) for approximately $2.5 \mathrm{~h}$ per day (100 cigarettes), 5 days per week, and last 2 weeks. Control subjects $(\mathrm{n}=4)$ were exposed to filtered room air. Mouse elastin (E6402-SPEC) was purchased from Sigma-Aldrich. $2 \mathrm{mg} / \mathrm{ml}$ elastin was suspended in sterile saline and sonicated. $100 \mu \mathrm{g}$ elastin in $50 \mu \mathrm{l}$ saline was administered intratracheally for 3 times at day 29,30, and 31, and mice were sacrificed $48 \mathrm{~h}$ after the last elastin challenge. The detailed experimental protocol refers to the previous study [6].

CS model: Mice $(n=6)$ were exposed to CS in a stainless-steel chamber using a whole-body smoke exposure system (TE-10, Teague Enterprises, Woodland, CA, USA) for approximately 10 times per day (5 cigarettes for each time), 5 days per week, and last 3 months. Control subjects $(n=5)$ were exposed to filtered room air.

\section{WNT/ $\beta$-catenin signaling activation in vivo}

The WNT/ $\beta$-catenin signaling in the lungs from $\mathrm{C} 57 \mathrm{BL} / 6$ mice was activated via intraperitoneal injection of lithium chloride $(\mathrm{LiCl})(200 \mathrm{mg} / \mathrm{Kg} / \mathrm{BW} /$ day $) . \mathrm{LiCl}$ is a substituted compound used as activator to evaluate the participation of $\mathrm{WNT} / \beta$-catenin signaling pathway. Like canonical WNT ligands, $\mathrm{LiCl}$ can suppresses the $\beta$-catenin destruction complex (Axin/ APC/ CK1/ GSK3 $\beta$ ) by inhibiting GSK-3 $\beta$ [7] (Fig. 3A). LiCl was diluted in sterile water and the fresh stock was prepared for every injection. CE model or air control subjects were treated with $\mathrm{LiCl}$ or normal saline (NS) for 5 times at day 29, 30, 31, 32 and 33 (Air $+\mathrm{NS}, \mathrm{n}=5$; $\mathrm{CE}+\mathrm{NS}, \mathrm{n}=4$; Air $+\mathrm{LiCl}, \mathrm{n}=5$; $\mathrm{CE}+\mathrm{LiCl}, \mathrm{n}=6$ ). Then mice were sacrificed $5 \mathrm{~h}$ after the last $\mathrm{LiCl}$ injection.

\section{RNA sequencing and data analysis}

Total RNA from PBMC of four patients with AECOPD, four patients with stable COPD, and five control subjects was extracted using RNAiso Reagent (TaKaRa Company, Dalian, China) according to the manufacturer's instructions. $2 \mu \mathrm{g}$ RNA per sample was used as input material for the RNA sample preparations. Sequencing libraries were generated using NEBNext ${ }^{\circledR}$ Ultra $^{\text {TM }}$ RNA Library Prep Kit for Illumina ${ }^{\circledR}$ (\#E7530L, NEB, USA) following the manufacturer's recommendations and index codes were added to attribute sequences to each sample. Briefly, mRNA was purified from total RNA using poly-T oligo-attached magnetic beads. Fragmentation was carried out using divalent cations under elevated temperature in NEBNext First Strand Synthesis Reaction Buffer (5X). cDNA was synthesized by reverse transcription with a reverse transcriptase kit (Toyobo, Japan). The library fragments were purified with QiaQuick PCR kits and elution with EB buffer, then end repair, A-tailing, and adapter ligation were implemented. The aimed products were retrieved by agarose gel electrophoresis and PCR was performed, then the library was completed. Transcriptome sequencing was performed on the Illumina Hiseq xTen platform.

Raw Data was processed with Perl scripts to ensure the quality of data used in further analysis. DESeq (v1.16) was used for differential gene expression analysis between two samples with biological replicates using a model based on the negative binomial distribution. The p-value could be assigned to each gene and adjusted by Benjamini and Hochberg's approach for controlling the false discovery rate. Genes with $\mathrm{q} \leq 0.05$ and $\mid \log _{2}$ Ratio $\mid \geq 1$ are identified as DEGs. The KEGG (Kyoto Encyclopedia of Genes and Genomes, http://www.kegg.jp/) enrichment of DEGs was implemented by the hypergeometric test, in which p-value was adjusted by multiple comparisons as q-value, which less than 0.05 was considered as significant enrichment.

\section{Quantitative real-time PCR}

Total RNA from PBMC of 30 patients with AECOPD, 27 patients with stable COPD, and 35 control subjects or the lungs of mice was extracted using RNAiso Reagent (TaKaRa Company, Dalian, China) according to the manufacturer's instructions. Reverse transcription was performed with a reverse transcriptase kit (Toyobo, Japan). Real-time PCR analysis of 9 human genes (LGR6, FZD4, and $C T N N B 1$, etc.) and 11 mouse genes (LGR6, FZD4, and $C T N N B 1$, etc.) were measured using specific primers (see Additional file 1) and gene expression assays on the ABI ViiA 7 Real Time PCR System (Applied Biosystems, United States of America). $2^{-\Delta \Delta C T}$ values was calculated as the relative mRNA level of genes.

\section{ELISA}

The concentration of $\beta$-catenin (CTNNB1) (BioVision, \# K3381-100) in human plasma was quantified using ELISA Kit according to the manufacturer's protocol.

\section{Immunofluorescence}

Immunofluorescent staining was used to quantify phosphorylated $\beta$-catenin $(p-\beta$-catenin) in the PBMC of human and lung tissue of mice. PBMC was isolated according to previous study [6], and fixed on the slide with a cytospin (Thermo Fisher Scientific, Cheshire, UK). $\mathrm{PBMC}$ and lung tissue were stained using the primary 
antibodies, p- $\beta$-catenin (SATTA CRUZ, sc-57535) and secondary antibodies. And then counterstained with DAPI. Slides were imaged under fluorescent microscopy with the appropriate excitation and emission filter, digitally recorded. The specific fluorescence was analyzed using Case Viewer (2.4.0). The proportion of fluorescent positive cells in each photo of PBMC was counted, and the mean value was used to represent the relative number of positive $\mathrm{p}-\beta$-catenin cells in each slide. Each scanogram of lung tissue was divided into 4-7 sections with equal area centered on the airway, and the average score was obtained according to the distribution of fluorescence positive cells. Relative positive $\mathrm{p}-\beta$-catenin cells were analyzed at $10 \times$ images by a blinded participant using a 5-point scale as follows: airway surrounded by a monolayer of positive cells -1 , airway surrounded by multiple layers of localized scattered positive cells -2 , airway surrounded by multiple layers of extensive scattered positive cells or some of the cells are clustered (sparse)-3, airway surrounded by multiple layers of positive cells with some of the cells are clustered (dense) - 4, airway surrounded by multiple layers of extensive positive cells with multiple positive cell masses (dense) -5 .

\section{Western blot analysis}

The lung tissue was prepared with RIPA buffer (BL504A, Biosharp, Shanghai, China) containing protease inhibitors (BL507A, Biosharp, Shanghai, China). The supernatants of lung tissue were run on gels and incubated with relevant antibodies, $\mathrm{p}-\beta$-catenin (SATTA CRUZ, sc-57535). Actin was used as a loading control. Quantification was performed by densitometry and analyzed using Image Studio Lite (LI-COR Biosciences, Lincoln, NE, USA).

\section{H\&E staining}

Morphological analysis of lung tissue sections was done by $H \& E$ staining (American Mastertech stain kits, \#KTHNEPT), following manufacturer recommendations.
Histological changes were analyzed under microscopy at $20 \times$.

\section{Statistical analysis}

Data were analyzed using GraphPad Prism 8.0 (GraphPad Software, La Jolla, CA, USA). The Student's t-test was used to determine the relationship between two groups. One-way analysis of variance (ANOVA) with Newman-keuls test was used to analyze the statistical differences among three or more groups. Data are expressed as mean \pm SEM and $P<0.05$ was considered statistically significant.

\section{Results \\ Demographic characteristics}

We used 13 subjects to analyze the DEGs by RNA-seq. Basic demographic characteristics for control subjects, patients with stable COPD or AECOPD are summarized in Table 1. The patient samples were matched for age, gender, smoking history, body mass index (BMI) and basic disease. The forced expiratory volume in $1 \mathrm{~s}$ $\left(\mathrm{FEV}_{1}, \%\right.$ Predicted) in stable COPD and AECOPD were $61.58 \pm 11.19$ (\%) and $45.23 \pm 20.97$ (\%), respectively, with no significant differences. Forced expiratory volume in $1 \mathrm{~s} /$ forced vital capacity $\left(\mathrm{FEV}_{1} / \mathrm{FVC}, \%\right)$ in stable COPD and AECOPD were $57.46 \pm 13.47$ (\%) and $49.10 \pm 15.35$ (\%), respectively, with no significant differences. The control subjects had no respiratory symptoms and no previous chronic airway disease.

Then, 92 subjects were used for qPCR verification, including 35 control subjects, 27 patients with stable COPD and 30 patients with AECOPD (Table 2). The patient samples were matched for age, current smoking, $\mathrm{BMI}$ and basic disease. $\mathrm{FEV}_{1} /$ Predicted in stable COPD and AECOPD were $53.33 \pm 14.64(\%)$ and $54.71 \pm 26.09$ (\%), respectively, with no significant differences. $\mathrm{FEV}_{1} /$ FVC in stable COPD and AECOPD was $51.70 \pm 11.18$

Table 1 Demographic of included subjects used for RNA-seq

\begin{tabular}{llll}
\hline & Control & Stable COPD & AECOPD \\
\hline Samples, N & 5 & 4 & 4 \\
Age, years & $76.80 \pm 8.66$ & $68.50 \pm 5.41$ & $74.00 \pm 3.39$ \\
Sex & 4 male, 1 female & 4 male & 3 male, 1 female \\
Smoking status & 1 current, 2 former, 2 never & 2 current, 1 former, 1 never & 1 current, 2 former, 1 never \\
BMl, kg/m ${ }^{2}$ & $23.99 \pm 2.95$ & $23.54 \pm 2.52$ & $22.85 \pm 3.90$ \\
FEV $1, \%$ Predicted & NA & $61.58 \pm 11.19$ & $45.23 \pm 20.97$ \\
FEV 1 FVC ratio, $\%$ & NA & $57.46 \pm 13.47$ & $49.10 \pm 15.35$ \\
Basic disease & Hypertension, diabetes & Hypertension, coronary heart disease & Hypertension, coronary heart disease
\end{tabular}

COPD chronic obstructive pulmonary disease, $A E C O P D$ acute exacerbation of chronic obstructive pulmonary disease, $B M I$ body mass index, $N A$ not applicable 
Table 2 Demographics of independent cohort used for validation

\begin{tabular}{llll}
\hline & Control & Stable COPD & AECOPD \\
\hline Samples, N & 35 & 27 & 30 \\
Age, years & $67.66 \pm 7.80$ & $68.00 \pm 8.00$ & $74.17 \pm 7.59$ \\
Sex & 25 male, 10 female & 27 male & 29 male, 1 female \\
Smoking status & 13 current, 12 former, 10 never & 11 current, 11 former, 5 never & 10 current, 18 former, 2 never \\
${\text { BMl, } \mathrm{kg} / \mathrm{m}^{2}}^{2}$ & $24.97 \pm 3.08$ & $22.93 \pm 2.52$ & $21.42 \pm 3.22$ \\
FEV $_{1}, \%$ Predicted & NA & $53.33 \pm 14.64$ & $54.71 \pm 26.09$ \\
FEV $_{1} /$ FV ratio, $\%$ & NA & $51.70 \pm 11.18$ & $49.05 \pm 14.58$ \\
Basic disease & Hypertension, diabetes & Hypertension, coronary heart disease & Hypertension, coronary heart disease \\
\hline
\end{tabular}

$C O P D$ chronic obstructive pulmonary disease, $A E C O P D$ acute exacerbation of chronic obstructive pulmonary disease, $B M I$ body mass index, $N A$ not applicable

(\%) and $49.05 \pm 14.58$ (\%), respectively, with no significant differences. The control subjects had no respiratory symptoms and no previous chronic airway disease.

\section{Multiple AECOPD-related DEGs identified by RNA-seq}

The genes with twofold difference in gene expression and $P$ value less than 0.05 were regarded as DEGs. We identified 1572 genes significantly differentially expressed between the stable COPD group and the control group, 1989 genes between the AECOPD group and the control group, and 405 genes between the AECOPD group and the stable COPD group. The number of up-regulated and down-regulated DEGs between groups was shown in Fig. 1A, B. According to the characteristics of progression from stable phase to acute exacerbation of COPD, we further screened the up-regulated and down-regulated DEGs in AECOPD. Screening criteria for up-regulated DEGs: The gene expression in the control group was 1.1 times less than that in the stable COPD group, and the gene expression in the AECOPD group was significantly higher than that in the stable COPD group. Screening criteria for down-regulated DEGs: The gene expression in the control group was 0.9 times more than that in the stable COPD group, and the gene expression in the AECOPD group was significantly lower than that in the stable COPD group. According to the screening criteria, a total of 54 up-regulated genes and 111 down-regulated genes in the AECOPD group were obtained (Fig. 1C). With the FPKM value of DEGs as the expression level, a hierarchical clustering analysis was conducted. There were significant differences in gene expression profiles among the three groups, indicating that the changes in gene expression levels were related to the pathogenesis of AECOPD. The regions with different distances represent different gene clustering information, and genes with similar expression patterns may have similar functions or participate in the same biological process (Fig. 1D).

\section{AECOPD-related signaling pathways obtained by KEGG pathway analysis}

To clarify the signaling pathways in which the DEGs were involved, KEGG pathway enrichment analysis was conducted. The top 20 pathways are shown in Fig. 2A. Multiple AECOPD-related signaling pathways were further obtained by using the filter conditions: the number of gene enrichment in the pathway is no less than three, and obvious pathogen infection-related pathways and other disease pathways were excluded. We identified 16 signaling pathways that were potentially associated with the pathogenesis of AECOPD, including phosphoinositide 3-kinase/serine threonine-protein kinase (PI3K/Akt) signaling pathway, mitogen-activated protein kinases (MAPK) signaling pathway, extracellular matrix (ECM)receptor interaction, and WNT signaling pathway, etc. (Fig. 2B). The RNA-seq results showed that compared with the control group and the stable COPD group, the expressions of LGR6 and FOSL1 in the WNT pathway were significantly down-regulated, and the expressions of FRAT2 were significantly up-regulated in the AECOPD group.

\section{Validation of down-regulated WNT/ $\beta$-catenin pathway in AECOPD}

Previous studies have shown that down-regulation of $\mathrm{WNT} / \beta$-catenin signaling pathway is associated with impaired lung tissue repair [8-10]. The relationship of $\mathrm{WNT} / \beta$-catenin signaling genes was shown in Fig. 3A. QPCR of 92 peripheral blood samples (27 patients with stable COPD, 30 patients with AECOPD, and 35 healthy controls) was used to verify the accuracy of RNA-seq results and to elucidate the expression of WNT/ $\beta$-catenin signaling genes in the blood of AECOPD patients. As depicted in Fig. 3B, compared 
A

\begin{tabular}{cccc}
\hline Groups & up-regulation & down-regulation & total \\
\hline Stable vs. Normal & 965 & 607 & 1572 \\
Acute vs. Normal & 1154 & 835 & 1989 \\
Acute vs. Stable & 135 & 270 & 405 \\
\hline
\end{tabular}

B
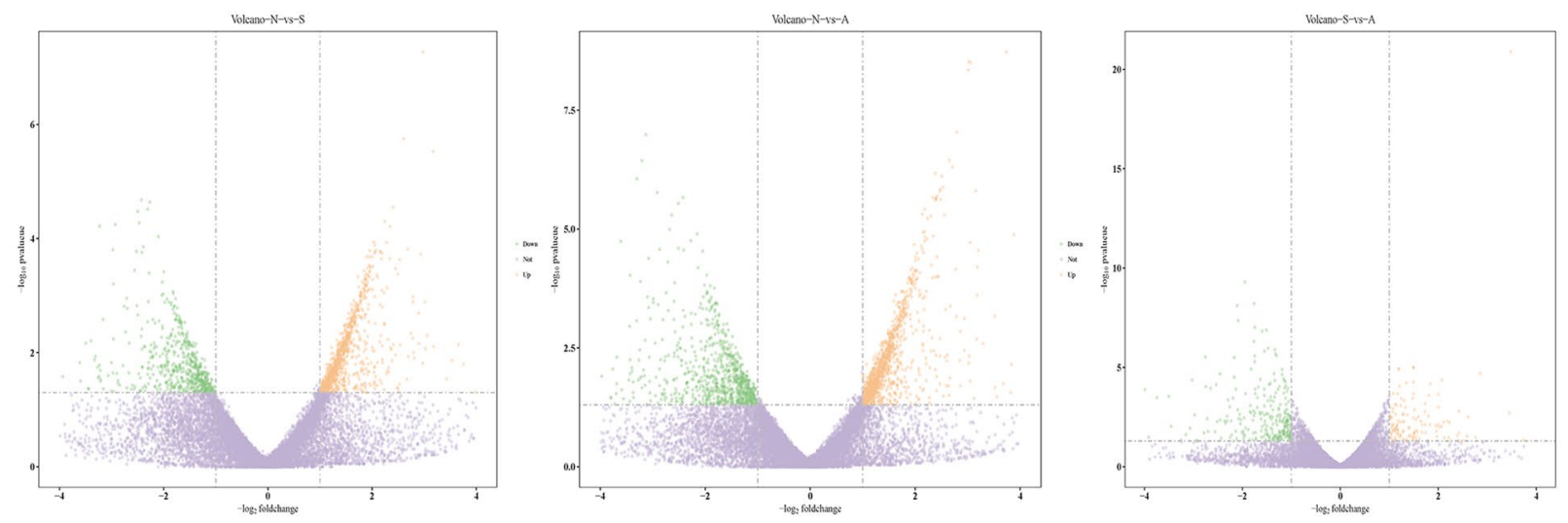

C

D

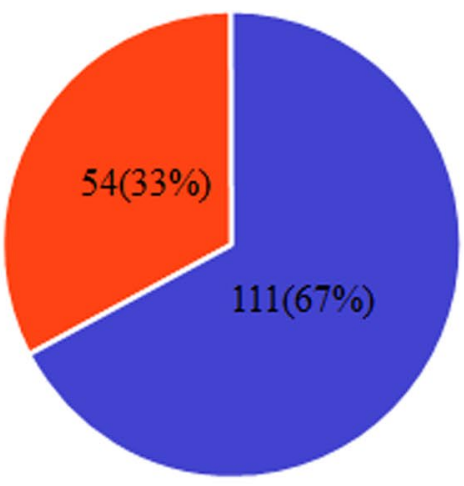

- up-regulation

- down-regulation

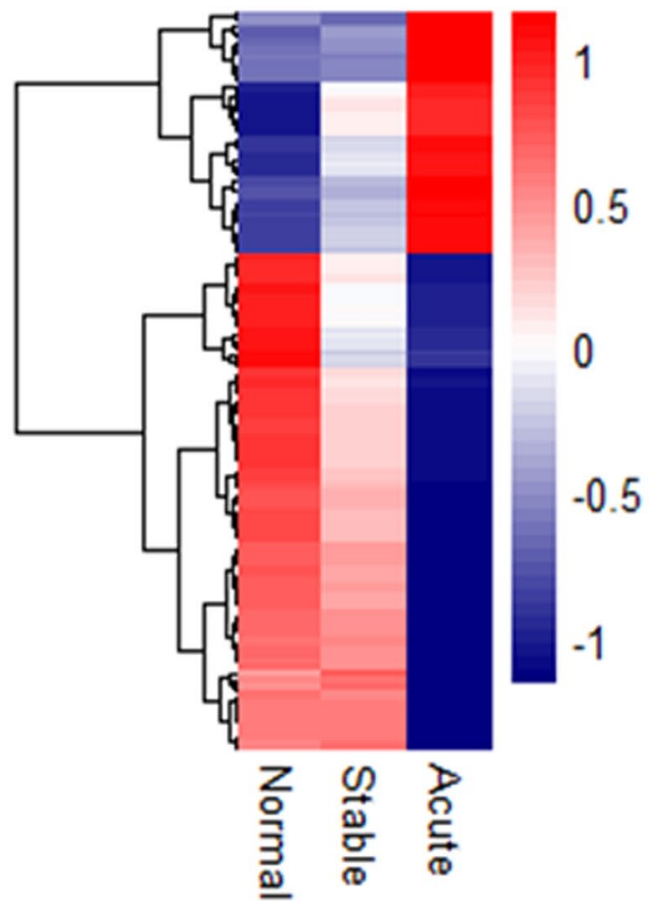

Fig. 1 AECOPD-related DEGs identified by differential expression analysis. A The number of DEGs between the stable COPD group and the control group, the AECOPD group and the control group, the AECOPD group and the stable COPD group, respectively. B The Volcano Plot of DEGs. Each point in the Volcano Plot represents a gene, the horizontal axis represents the $-\log _{2}$ (fold change) of a gene expression in two groups. $-\log _{10}(\mathrm{p}$ value) as the ordinate represents the statistical significance of the change in gene expression. The yellow dots, green dots and purple dots represent up-regulated, down-regulated and non-differentially expressed genes, respectively. C According to the disease progression to screen DEGs. D The clustering heat maps of DEGs. The abscissa represents the three groups, the ordinate represents the DEGs and the clustering results of the genes.

The color represents the gene expression level, the deeper the red color, the higher the gene expression level 
A

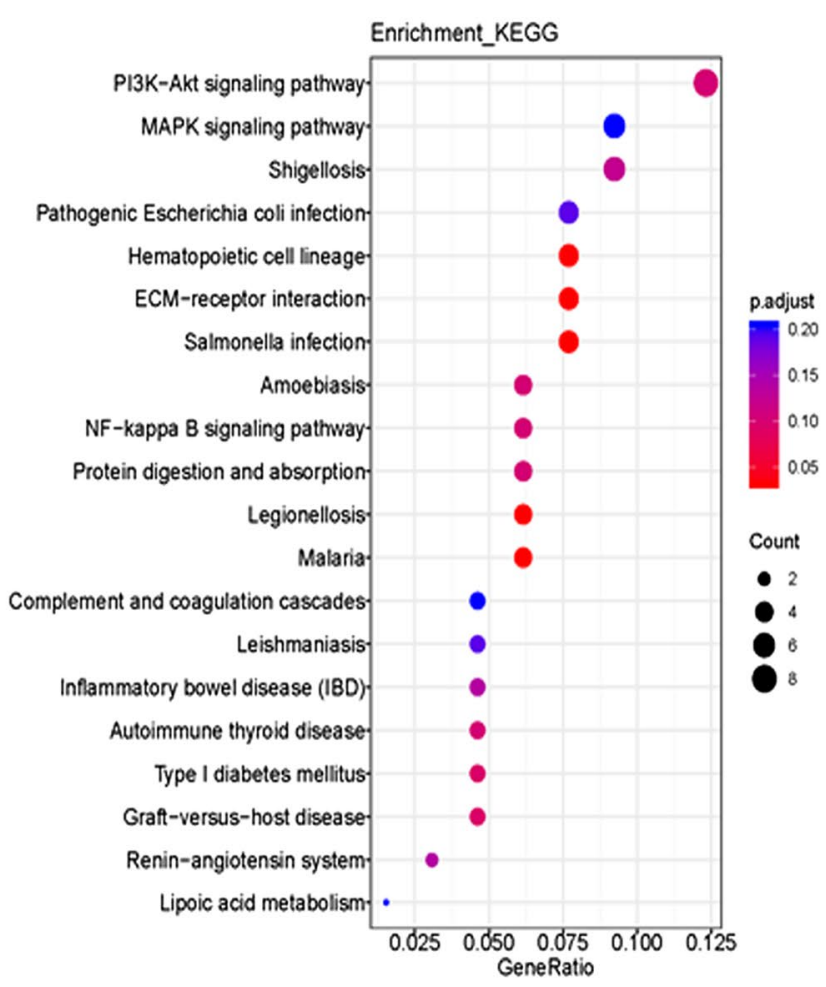

B

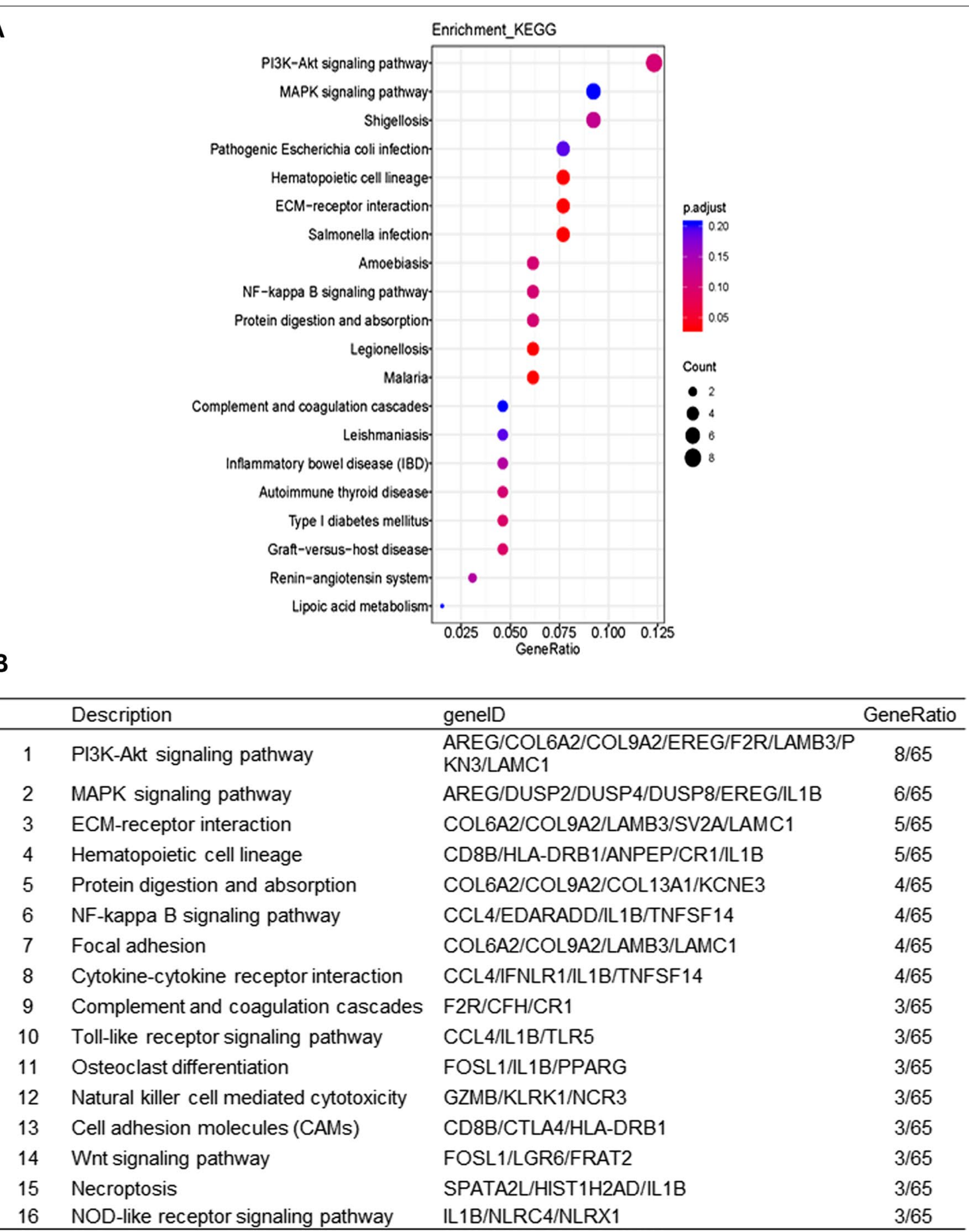

Fig. 2 AECOPD-related signaling pathways obtained by KEGG analysis. A KEGG pathway enrichment analysis of DEGs. The vertical axis represents signaling pathways. The horizontal axis represents the gene ratio, which is, the number of DEGs to the number of annotated genes in pathways. The size of the dot indicates the number of DEGs in the pathway, and the color of the dot corresponds to different adjusted p value ranges. B The pathways and DEGs associated with the pathogenesis of AECOPD. Selection criteria: 1. The number of DEGs enriched in pathways is not less than three. 2. Exclude specific pathogen infection, and disease pathways 
A

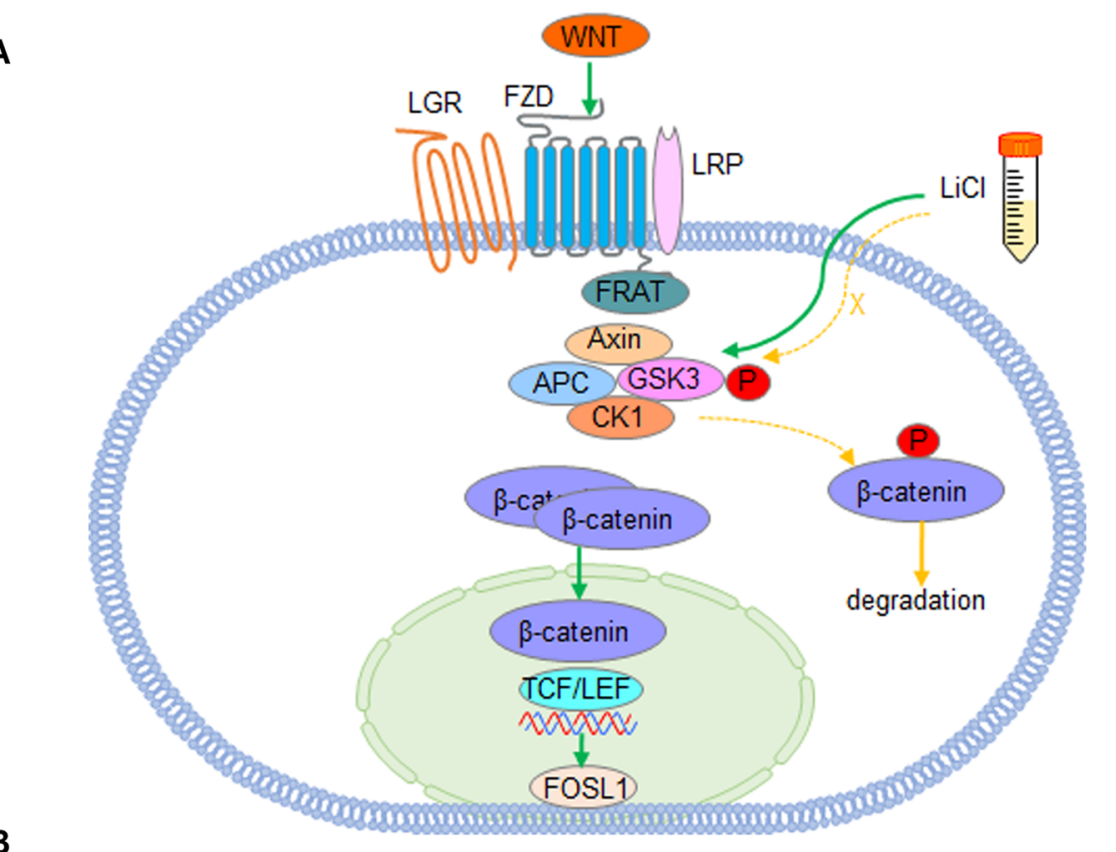

B

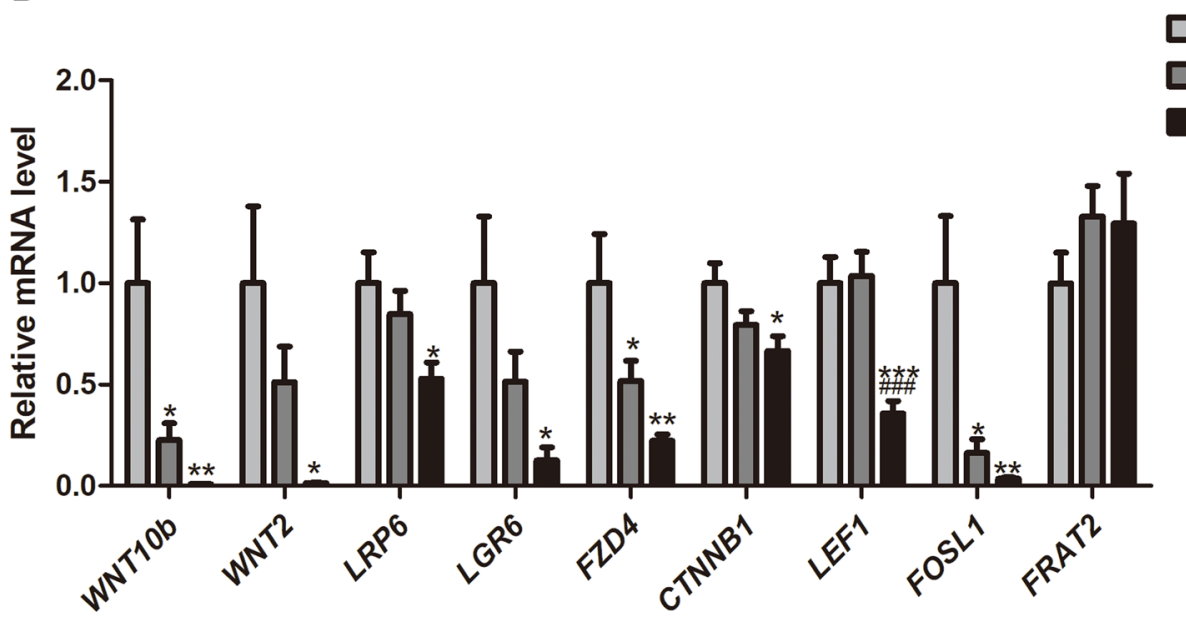

Fig. 3 Validation of down-regulated WNT/ß-catenin pathway in AECOPD. A WNT/ß-catenin signaling pathway. The WNT ligands bind to the receptors, including the FZD family, the coreceptor LRP 5/6 and LGR4-6, downstream signaling molecules are activated, the destruction complex (Axin/ APC/ CK1/ GSK-3) is inhibited. The accumulation and translocation of dephosphorylated $\beta$-catenin to the nucleus drives the expression of T-cell factor/lymphoid enhancer-binding factor (TCF/LEF)-dependent genes. When there are no WNT ligands or fewer WNT ligands and receptors, the destruction complex is activated, causing phosphorylation of $\beta$-catenin to increase and eventually be degraded. Exogenous addition of lithium chloride can also inhibit the destruction complex, promotes $\beta$-catenin - mediated gene transcription. B The mRNA levels of WNT106, WNT2, LRP6, LGR6, FZD4, CTNNB1, LEF1, FOSL1, and FRAT2 in the control group $(n=35)$, the stable COPD group $(n=27)$ and the AECOPD group ( $n=30)$. Results are presented as relative mRNA level (mean \pm SEM). Stable or Acute vs. Normal, ${ }^{*} P<0.05,{ }^{* *} P<0.01,{ }^{* *} P<0.001$ by one-way ANOVA. Acute vs. Stable, ${ }^{\# \#} P<0.001$ by one-way ANOVA

with the control group, significant down-regulation was observed for WNT10b, WNT2, LRP6, LGR6, FZD4, $C T N N B 1, L E F 1$, and FOSL1 in AECOPD $(P<0.05)$, and partial WNT/ $\beta$-catenin signaling components including WNT10b, FZD4, and FOSL1 were significantly down-regulated in stable COPD $(P<0.05)$. Compared with the stable COPD, LEF1 was significantly downregulated in AECOPD $(P<0.001)$. Actually, most of the other genes were further down-regulated in AECOPD, although with no significant difference. Besides, the mRNA level of FRAT2 among the three groups has no significant difference. 
Expression of WNT/ $\beta$-catenin pathway proteins in AECOPD To further explore the expression of proteins associated with $\mathrm{WNT} / \beta$-catenin signaling pathway and search for specific biomarkers of AECOPD, we performed ELISA of $\beta$-catenin in plasma and immunofluorescence of $p-\beta$ catenin in PBMC. It revealed that $\beta$-catenin was significantly down-regulated in stable COPD and AECOPD $(P<0.01)$, but no significant difference between the stable COPD and AECOPD (Fig. 4A). On the other side, $\mathrm{p}-\beta$-catenin was significantly up-regulated in AECOPD compared with the stable COPD and the control group $(P<0.05)$ (Fig. 4B, C).

\section{Alterations of WNT/ $\beta$-catenin pathway in experimental COPD models}

The above results indicated that the $\mathrm{WNT} / \beta$-catenin signaling is down-regulated in the blood of patients with AECOPD. To further elucidate the expression of the WNT/ $\beta$-catenin signaling pathway in lung tissue, two COPD mouse models were used. Given that there is no reliable mouse model of AECOPD, we referred to an acute inflammation model of cigarette smoke sensitization combining elastin challenge, which showed relatively high levels of neutrophilic inflammation and mucus hyperproduction in airways [6]. Mice were exposed to CS for 2 weeks and were hosted at room
A

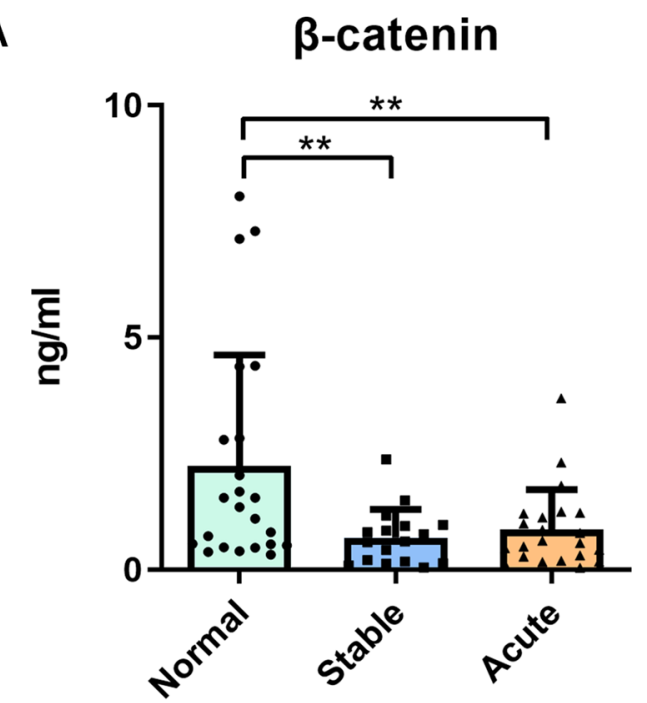

B

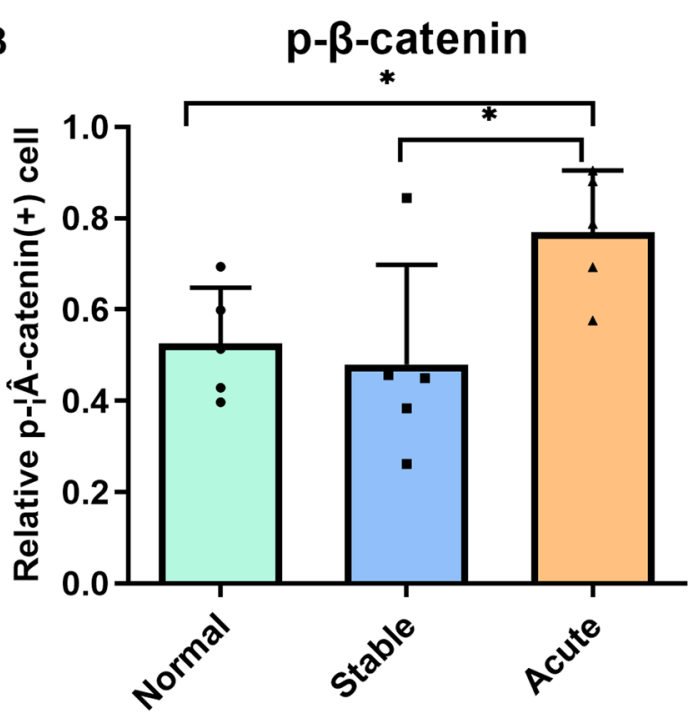

C

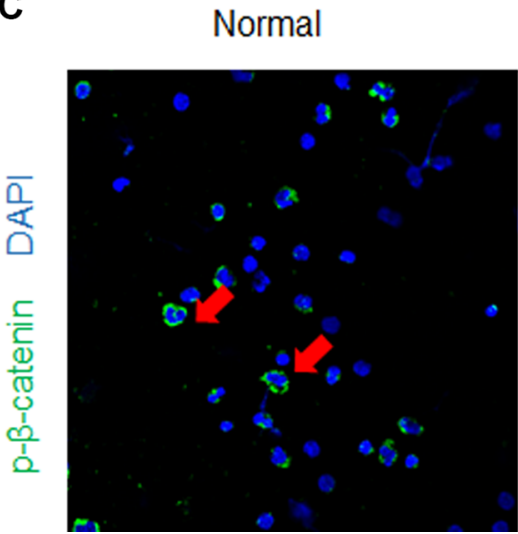

Stable

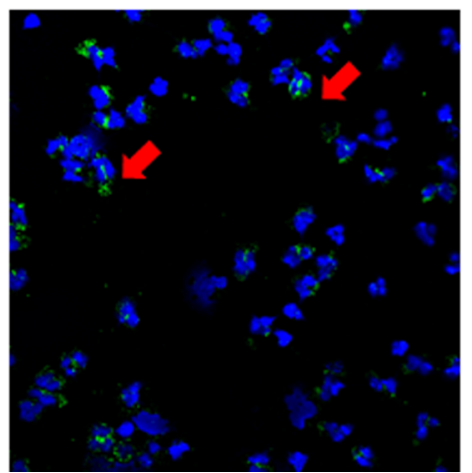

Acute

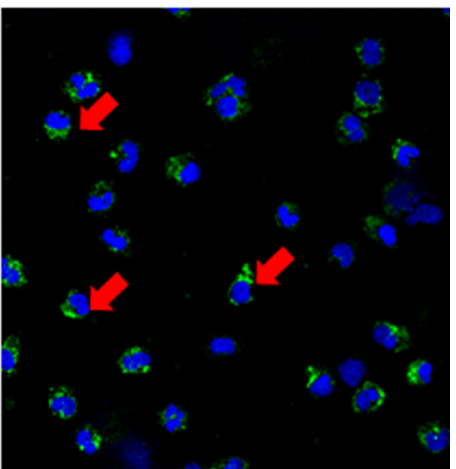

Fig. 4 Alterations of $\beta$-catenin and its phosphorylation in AECOPD. A The expression of $\beta$-catenin protein in plasma of control subjects ( $\mathrm{n}=23$ ), patients with stable COPD $(n=17)$ and patients with AECOPD $(n=22)$ was analyzed by ELISA. Results are presented as protein concentration (mean \pm SEM). B, C The expression of phosphorylated $\beta$-catenin protein in PBMC of control subjects $(n=5)$, patients with stable COPD $(n=5)$ and patients with AECOPD $(n=5)$ was analyzed by immunofluorescence. B Results are presented as relative number of positive $p$ - $\beta$-catenin cells (mean \pm SEM). C Immunofluorescent staining of PBMC. Green fluorescence represents positive phosphorylated $\beta$-catenin cells (red arrowheads). Blue fluorescence represents DAPI. ${ }^{*} P<0.05,{ }^{*} P<0.01$ by one-way ANOVA 
air for another 2 weeks, then challenged with elastin intratracheally on three consecutive days (Fig. 5A). Most of the $\mathrm{WNT} / \beta$-catenin pathway components, including WNT10b, WNT2, LRP6, LGR6, FZD4, $C T N N B 1$, and $L E F 1$, were significantly down-regulated in CE mice $(P<0.05)$, except FOSL1 (Fig. 5B). The expression of $\mathrm{p}-\beta$-catenin protein was significantly upregulated in CE mice $(P<0.05)$ (Fig. $5 \mathrm{C}, \mathrm{D})$.

In the traditional CS-induced COPD model, mice were exposed to CS 5 days a week for 3 months (Fig. 5E). The mRNA of LRP6, LGR6, FZD4, and $C T N N B 1$ was also significantly down-regulated in CS mice $(P<0.05)$. The mRNA of WNT10b was significantly up-regulated in CS mice $(P<0.05)$. No significant difference was observed for WNT2, LEF1, and FOSL1 between CS mice and air control mice (Fig. 5F).

\section{Activation of the WNT/ $\beta$-catenin pathway reduced phosphorylated- $\beta$-catenin and airway inflammation} Finally, we investigated whether $\mathrm{WNT} / \beta$-catenin signaling pathway activation could improve the pathological changes of lung tissue. Lithium chloride $(\mathrm{LiCl})$, as a $\mathrm{WNT} / \beta$-catenin pathway activator, can inhibit the $\mathrm{p}-\beta$-catenin through GSK3 $\beta$. The dephosphorylated $\beta$-catenin increased in cytoplasm transfers to the nucleus, which mediates downstream signal transduction and gene expression [11]. Immunofluorescence and Western blot analysis of $\mathrm{p}-\beta$-catenin in the lung tissue revealed that the level of $\mathrm{p}-\beta$-catenin was significantly up-regulated in CE +NS mice $(P<0.01)$. Importantly, after treatment with $\mathrm{LiCl}$, the level of $\mathrm{p}-\beta$-catenin was significantly down-regulated in $\mathrm{CE}+\mathrm{LiCl}$ mice compared with $\mathrm{CE}+\mathrm{NS}$ mice $(P<0.05)$ (Fig. 6A-D). Moreover, as shown in Fig. 6E, extensive inflammation cells around the airway in CE mice have a remarkable reduction after $\mathrm{LiCl}$ injection. Correspondingly, the mRNA level of $I L-1 \beta, I L-6$, and $I L$ $17 A$ was significantly up-regulated in $\mathrm{CE}+\mathrm{NS}$ mice compared with Air + NS mice $(P<0.05)$ and was again markedly down-regulated in $\mathrm{CE}+\mathrm{LiCl}$ mice compared with $\mathrm{CE}+\mathrm{NS}$ mice $(P<0.05)$ (Fig. 6F).

\section{Discussion}

In this study, RNA-seq was used to obtain DEGs in the blood of different stages of COPD. Combined with bioinformatics analysis, multiple signaling pathways were found to participate in the pathogenesis of AECOPD, which is consistent with previous studies [9, 12-14]. Importantly, we demonstrated, for the first time, that the $\mathrm{WNT} / \beta$-catenin signaling pathway is decreased in patients with AECOPD. A key component of this pathway $p$ - $\beta$-catenin protein is up-regulated in the blood of patients with AECOPD. Down-regulation of WNT/ $\beta$ catenin signaling pathway was also observed in the lung tissues of experimental COPD models. Activation of $\mathrm{WNT} / \beta$-catenin signaling pathway can reduce the expression of $\mathrm{p}-\beta$-catenin protein and alleviate lung inflammation in CE model.

In the present study, RNA-seq was used to identify DEGs in the blood of patients with stable COPD and AECOPD, as well as control subjects. The number of DEGs obtained by RNA-seq was correlated with the number of biological replicates, the sequencing depth and the fold change. Studies have found that when the number of biological replicates was 3, 5 and 10, the statistical power to detect DEGs of twofold change was $87 \%$, $98 \%$ and $100 \%$, respectively [15]. For a certain number of biological replicates, increasing the sequencing depth will increase the number of DEGs detected, however, when the sequencing depth was above $10 \mathrm{M}$, the number of DEGs increased slowly [16]. In this study, we recruited 5 control subjects, 4 patients with stable COPD, and 4 patients with AECOPD for RNA-seq, with a sequencing depth of $40 \mathrm{M}$ and a fold change of 2 times, which can make the statistical power to detect DEGs close to $98 \%$. Moreover, the clinical characteristics of the subjects we recruited were similar. After RNA-seq and data processing, we obtained DEGs with good sequencing quality and high expression levels.

One of the aims of the present study was to identify and annotate the DEGs. Thousands of DEGs were revealed from the PBMC between different groups. And 54 up-regulated genes and 111 down-regulated genes in AECOPD were considered as disease-related genes, according to the characteristics of disease progression

\footnotetext{
(See figure on next page.)

Fig. 5 Altered WNT/ $\beta$-catenin pathway in experimental COPD models. A-D CS exposure following elastin challenge in mouse lung tissues. A Experimental outline. Mice were exposed to CS $(n=5)$ or room air $(n=4)$ for 2 weeks and were hosted at room air for another 2 weeks. Mice were then challenged with elastin (Eln, $100 \mu \mathrm{g}$ ) or normal saline (NS) intratracheally (i.t.) for 3 times at day 29, 30, and 31, and were sacrificed $48 \mathrm{~h}$ after the last elastin challenge. B The mRNA levels of WNT10b, WNT2, LRP6, LGR6, FZD4, CTNNB1, LEF1 and FOSL1 in lung tissue of CE and air control mouse models, were assessed by qPCR. Results are presented as relative mRNA level (mean \pm SEM). ${ }^{*} P<0.05,{ }^{* *} P<0.01,{ }^{* * *} P<0.001$ by the Student t-test. C Representative immunofluorescent staining of lung tissue. Green fluorescence represents positive phosphorylated $\beta$-catenin cells. Blue fluorescence represents DAPI. D Semi-quantification of positive phosphorylated $\beta$-catenin cells. E, F CS exposure in mouse lung tissues. E Experimental outline. Mice were exposed to cigarette smoke $(n=6)$ or filtered room air $(n=5)$, and lung tissue was obtained after 3 months. $\mathbf{F}$ The mRNA levels of WNT10b, WNT2, LRP6, LGR6, FZD4, CTNNB1, LEF1, and FOSL1 in lung tissue of CS and air control mouse models, were assessed by QPCR. Results are presented as relative mRNA level (mean \pm SEM). ${ }^{*} P<0.05,{ }^{* * *} P<0.001$ by the Student t-test
} 
A

Air/CS

Day 1

B

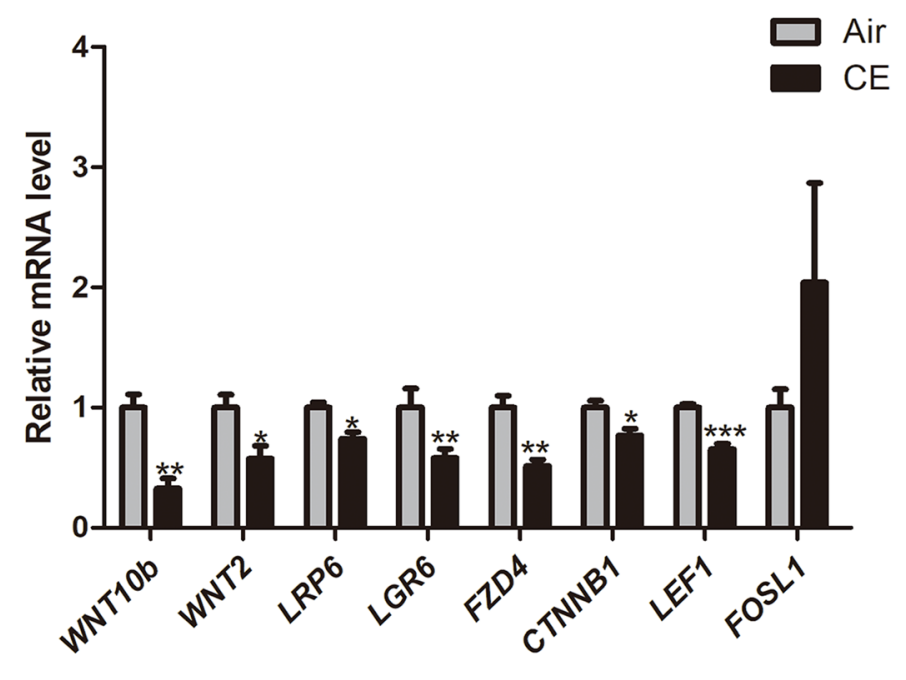

D

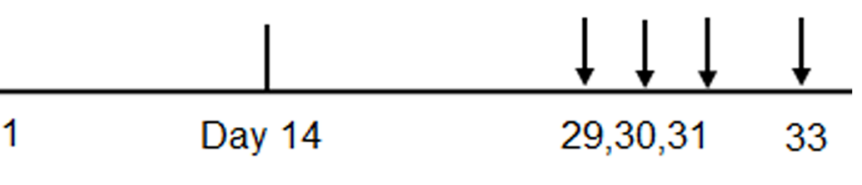

E

$\mathbf{F}$
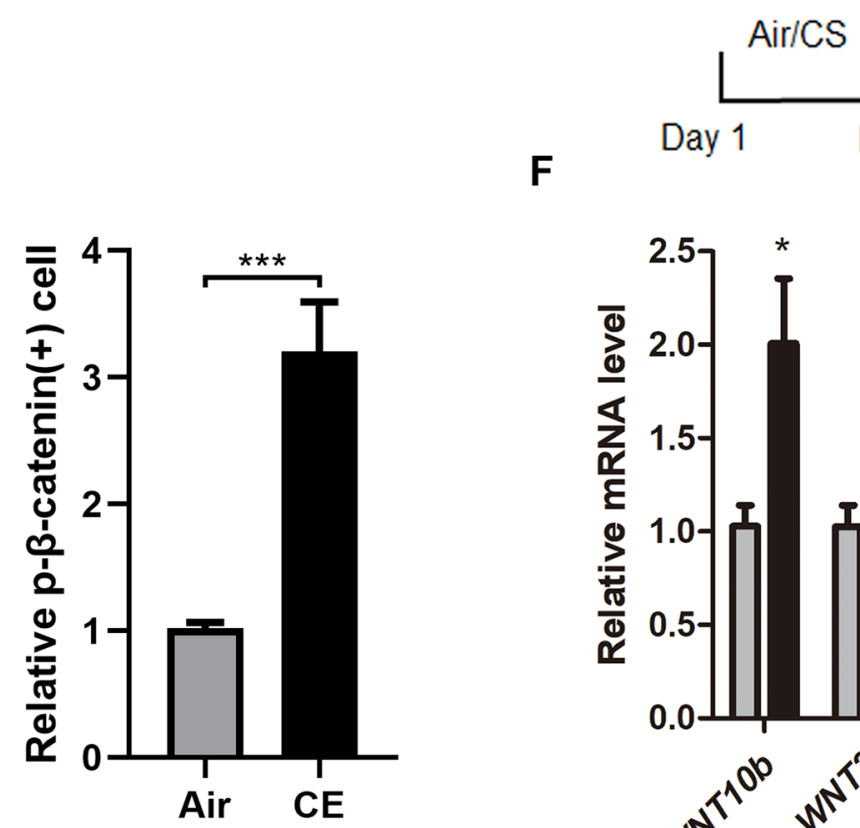

Day 1

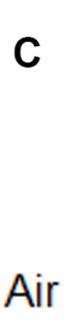

CE
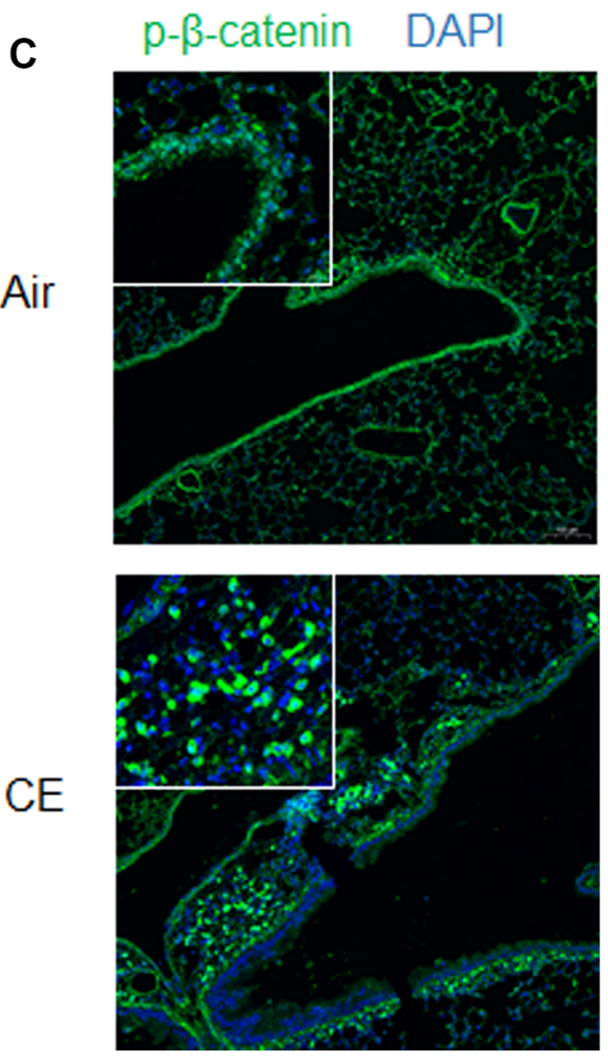

Sacrifice

Day 5

3 mon
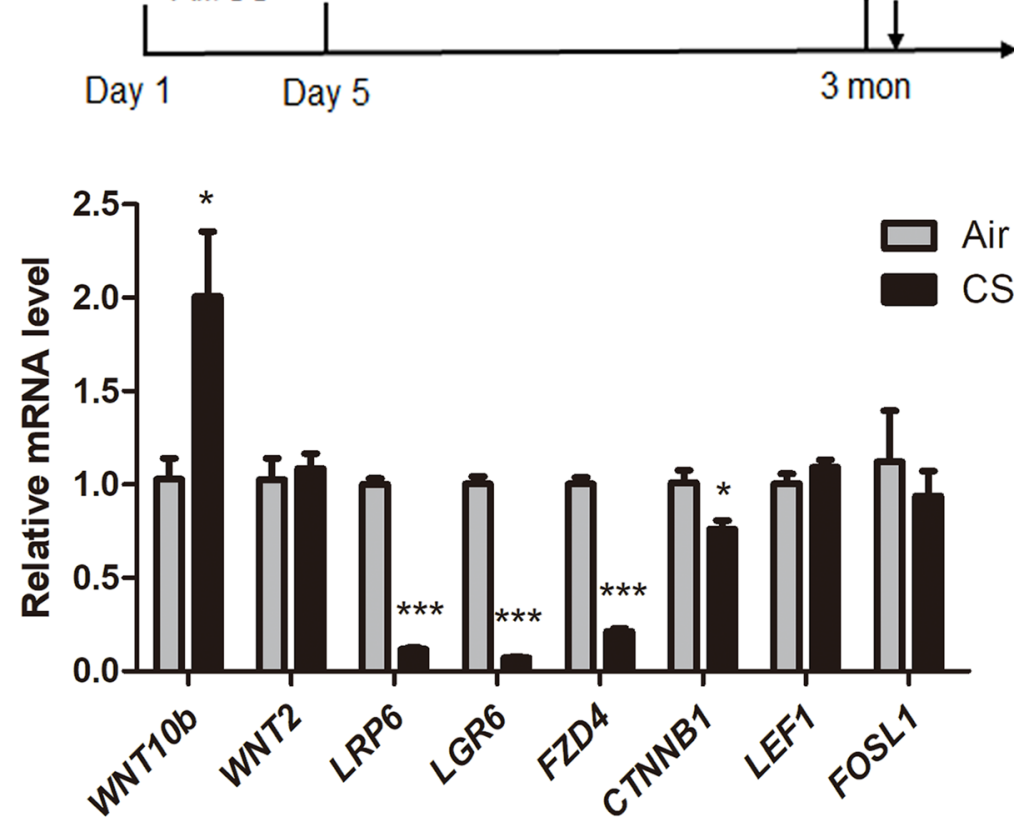

Fig. 5 (See legend on previous page.) 
from stable to acute exacerbation of COPD. To elucidate the biological processes involved in these genes, we used KEGG database for enrichment analysis and identified 16 signaling pathways that may be related to the pathogenesis of AECOPD. Some previous studies have demonstrated the correlation between the signaling pathways and the pathological process of COPD. PI3K signaling pathway is significantly activated and is associated with increased susceptibility to pulmonary infection in patients with COPD. Cigarette smoke extract can induce Akt degradation, activate the death-signaling pathway, and lead to cell death in normal human lung fibroblasts $[12,17]$. ECM protein promotes proliferation, migration, and adhesion of airway smooth muscle cells in COPD rat model by activating PI3K-Akt signaling pathway [18]. Activation of the p38 MAPK pathway appears to be involved in the pathogenesis of COPD, and drug inhibition of P38 MAPK can reduce the secretion of proinflammatory factors in alveolar macrophages. In clinical trials, treatment with p38 MAPK inhibitor for 6 weeks can improve $\mathrm{FEV}_{1}$ in COPD patients $[13,19,20]$.

Except for the above signaling pathways, we found that 3 DEGs enriched in WNT signaling pathway. The WNT family includes 19 glycoproteins, which interact with transmembrane receptors to mediate the signal transduction from cytoplasm to nucleus, thus regulating gene expression, causing cytoskeleton rearrangement, and changing cell polarity [21]. The canonical WNT signaling pathway relies on a key transcriptional coactivator, $\beta$-catenin. When the WNT ligands bind to their receptors, including the FZD family, the coreceptor LRP 5/6 and LGR4-6 (as a stabilizer for the two receptors), the destruction complex (Axin/ APC/ CK1/ GSK-3) is inhibited, and the phosphorylation of $\beta$-catenin is blocked by GSK-3. The accumulation and translocation of dephosphorylated $\beta$-catenin to the nucleus drives the expression of T-cell factor/lymphoid enhancer-binding factor (TCF/ LEF)-dependent genes [22, 23]. WNT signaling pathway plays an important role in the development and function of many organ systems, including the respiratory system. Dysfunction of WNT signaling pathway is related to the occurrence and development of many lung diseases, such as asthma, COPD, idiopathic pulmonary fibrosis, and non-small cell lung cancer. In studies on WNT signaling pathway and COPD, it has been demonstrated that $\mathrm{WNT} / \beta$-catenin pathway is involved in lung epithelial injury and repair, and the reduction of $\mathrm{WNT} / \beta$-catenin signaling pathway is associated with emphysema parenchymal tissue destruction and impaired repair capacity [9]. The WNT receptor FZD4 is decreased in human and experimental COPD which contributes to impaired alveolar repair capacity [8]. Considering the important role of $\mathrm{WNT} / \beta$-catenin pathway in stable COPD, whether it is involved in the pathological process of AECOPD aroused our interest.

Since RNA-Seq was conducted on a relatively small set of patients to reveal the transcriptome profiles, which provided the general understanding of the AECOPD patients compared with the controls and came out the key targets for the following validations and functional investigations. To validate the critical targets identified from our RNA-Seq analysis, validation examined by a more significant number of patients was performed. In addition, it will aid in concluding relatively reliable conclusions on our findings of these main targets. By qPCR, we found that the mRNA expression of WNT ligands (WNT10b, WNT2), WNT receptors (LRP6, LGR6, FZD4) and downstream signaling molecules (CTNNB1, LEF1, FOSL1) were down regulated in the PBMC of AECOPD patients. Importantly, to our knowledge, it is for the first time to identify that the expression of $\mathrm{p}-\beta$-catenin protein was up-regulated in the PBMC of AECOPD patients, which suggests its potential value as a novel biomarker of AECOPD.

To further evaluate the impact of $\mathrm{WNT} / \beta$-catenin signaling pathway during acute airway inflammation and stable COPD, we applied two different animal models, CE and CS exposure, respectively. The CE model has been demonstrated with much higher levels of neutrophilic airway inflammation, mucus hyperproduction, and predominant Th17 response than traditional CS model, somehow mimicking the bronchitis phenotype or AECOPD [6, 24, 25]. The down-regulation of $\mathrm{WNT} / \beta$-catenin signaling pathway was observed in both animal models, which emphasized that the decreased activity of WNT/ $\beta$-catenin pathway was not

\footnotetext{
(See figure on next page.)

Fig. 6 Activation of the WNT pathway reduces phosphorylated- $\beta$-catenin and COPD-like airway inflammation. Mice were exposed to CS or room air for 2 weeks and were hosted at room air for another 2 weeks. Mice were then challenged with elastin (Eln, $100 \mu \mathrm{g})$ or normal saline (NS) intratracheally (i.t.) for 3 times at day 29, 30, and 31, and were injected with lithium chloride (LiCl) or NS intraperitoneally for 5 times at day 29, 30, 31, 32 and 33 (Air + NS, $n=5 ; C E+N S, n=4 ; A i r+L i C l, n=5 ; C E+L i C l, n=6$ ). Then mice were sacrificed $5 \mathrm{~h}$ after the last LiCl injection. A Representative expression and localization of phosphorylated $\beta$-catenin in mice lung tissues by immunofluorescence. B Semi-quantitative analysis of the immunofluorescence results. Results are presented as relative number of positive phosphorylated $\beta$-catenin cells (mean \pm SEM). ${ }^{*} P<0.05,{ }^{* *} P<0.001$ by one-way ANOVA. C The expression of phosphorylated $\beta$-catenin in mice lung tissue was analyzed by Western Blot. $\mathbf{D}$ Semi-quantitative analysis of the Western Blot results. Results are presented as relative protein expression concentration $(m e a n \pm S E M)$. ${ }^{* *} P<0.01$ by one-way ANOVA. $\mathbf{E} H \& E$ staining for histologic assessment of lung tissue. $\mathbf{D}$ The mRNA levels of $I L-1 \beta, I L-6$ and $I L-17 A$. Results are presented as relative mRNA level (mean \pm SEM). CE + NS vs. Air + NS, ${ }^{*} P<0.05,{ }^{* *} P<0.01 ; C E+L i C l$ vs. CE $+N S,{ }^{\#} P<0.05,{ }^{\# \#} P<0.01$ by one-way ANOVA
} 


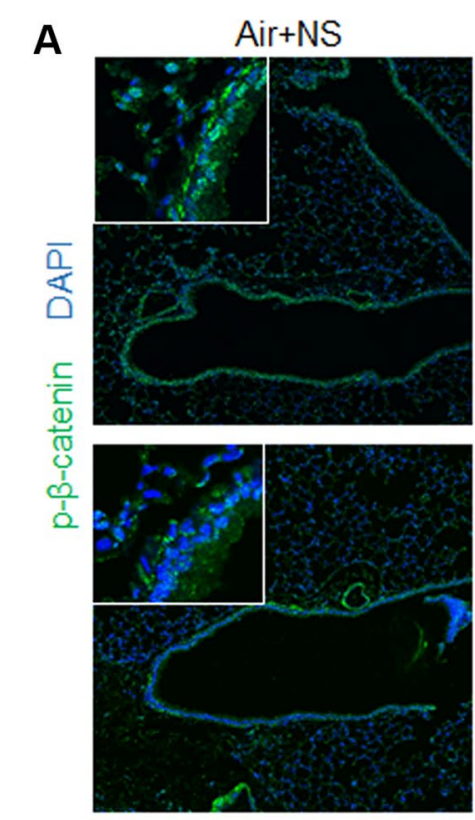

C

$$
\text { Air+LiCl }
$$

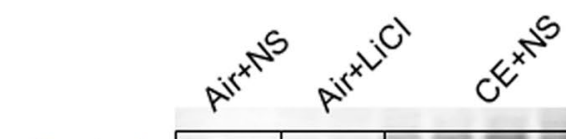

p- $\beta$-catenin

$$
\text { actin }
$$

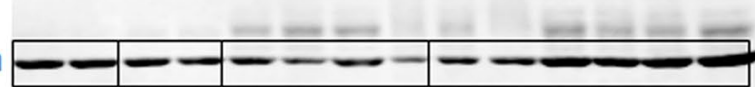

E

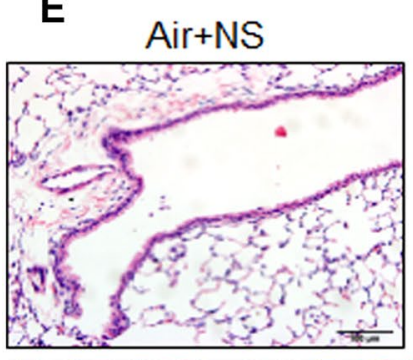
$\mathrm{Air}+\mathrm{LiCl}$

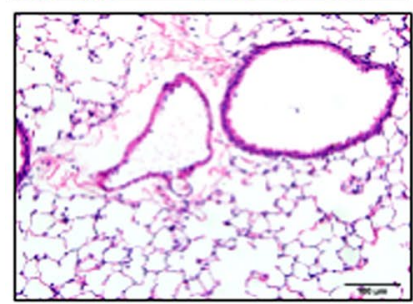

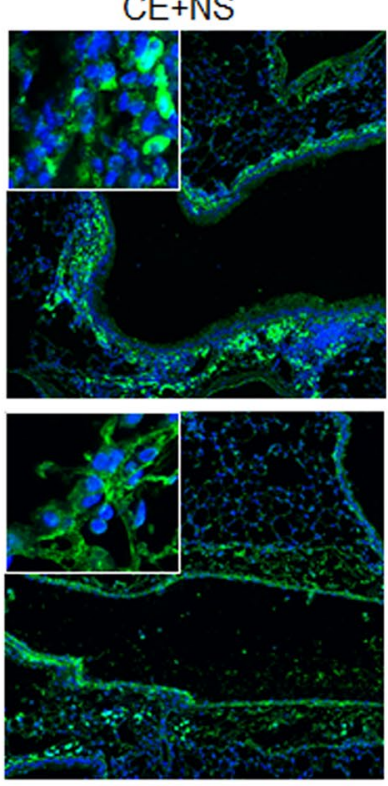

$\mathrm{CE}+\mathrm{LiCl}$
B

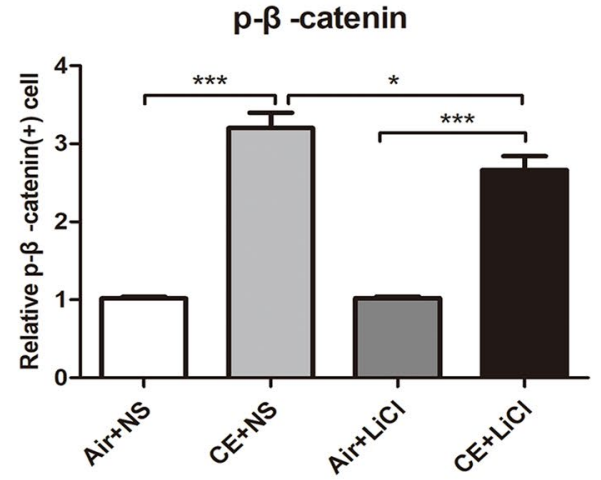

D

$p-\beta$-catenin

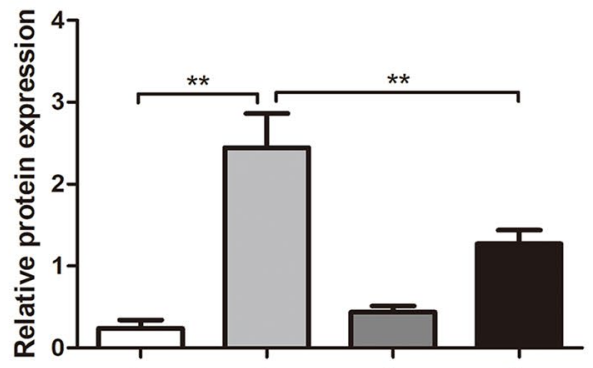

$\mathbf{F}$
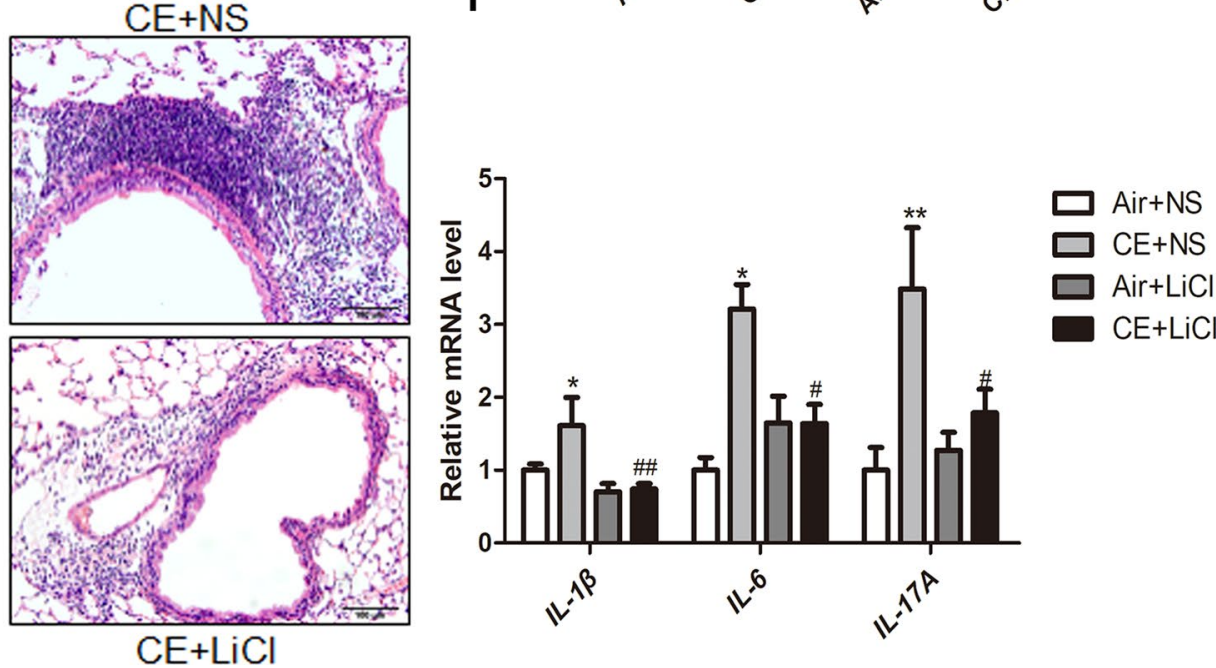

Fig. 6 (See legend on previous page.) 
only involved in the progression of COPD but might also be associated with the onset of acute exacerbation. Interestingly, activation of $\mathrm{WNT} / \beta$-catenin pathway by $\mathrm{LiCl}$ can reduce the expression of $\mathrm{p}-\beta$-catenin protein around the airway and improve lung inflammation in CE mice, further suggesting $\mathrm{p}-\beta$-catenin as a biomarker and a therapeutic target. In recent years, numbers of studies have reported that $\beta$-catenin participates in several inflammatory diseases, including acute lung injury [26], chronic rhinosinusitis [27], sepsis [28], osteoarthritis [29] and so on. Moreover, our results are in accordance with a previous publication, reporting that the lung inflammatory induced by cigarette smoke extract and airspace enlargement induced by elastin in mice can be alleviated by the WNT pathway activator, $\mathrm{LiCl}$, and it was associated with increased activation of erythroid-2 related factor-2 pathway [30].

Some limitations of this study are also worth discussing. Firstly, although the sample size of RNA-seq in this study was able to make the detection rate of DEGs close to $98 \%$, further studies with a larger sample size were needed to confirm our results. Secondly, it is worth further investigating the expression of $\mathrm{WNT} / \beta$-catenin pathway-related proteins in sputum of AECOPD patients. Thirdly, whether the value of $p$ - $\beta$-catenin as a potential biomarker of AECOPD is better than clinical indicators still needs to be explored, and it should be noted, immunostaining of $\mathrm{p}-\beta$-catenin is not as convenient as other common methods like ELISA for its clinical application. Finally, except the WNT/ $\beta$-catenin pathway, the role of other signaling pathways obtained by RNA-seq in the pathogenesis of AECOPD is worth further exploring.

In conclusion, we find 16 potential signaling pathways related to the pathogenesis of AECOPD, including PI3K/Akt signaling pathway, MAPK signaling pathway, and ECM- receptor interaction, et al. Remarkable, we demonstrated, for the first time, that the $\mathrm{WNT} / \beta$ catenin signaling pathway is decreased in patients with AECOPD and CE mouse model. Phosphorylated $\beta$-catenin protein is up-regulated in the blood of patients with AECOPD. Therapeutic activation of $\mathrm{WNT} / \beta$-catenin signaling pathway can alleviate lung inflammation in CE mouse model. As a new potential biomarker of AECOPD, $\mathrm{p}-\beta$-catenin is expected to provide a new research target for the early diagnosis and treatment of AECOPD.

\section{Abbreviations}

RNA-seq: RNA sequencing; PBMC: Peripheral blood mononuclear cells; DEGs: Differentially expressed genes; CS: Cigarette smoke; CE: Cigarette smoke sensitization and elastin challenge; $p$ - $\beta$-catenin: Phosphorylated $\beta$-catenin.

\section{Supplementary Information}

The online version contains supplementary material available at https://doi. org/10.1186/s12931-022-01950-w.

Additional file 1: Table S1. The primers sequence for $\mathrm{QPCR}$ of human blood. Table S2. The primers sequence for $\mathrm{PPCR}$ of mice lung tissue.

\section{Acknowledgements}

We would like to thank all investigators who recruited patients and all the patients who participated.

\section{Authors' contributions}

$\mathrm{HH}$ conceptualized the study. HW, YZ and NL wrote the manuscript and conducted data analysis and statistical analysis. HH, HW and LW conducted the methodology. YZ, NL and MY collected data. LZ, FC, YX and JL review and edit the manuscript. All authors read and approved the final manuscript.

\section{Funding}

This work was funded by the National Key R\&D Program of China [2017YFC1310604].

Availability of data and materials

The authors confirm that the data supporting the findings of the present study are available within the article.

\section{Declarations}

\section{Ethics approval and consent to participate}

The study was approved by the Institutional Review Board for Human Studies of Second Affiliated Hospital of Zhejiang University School of Medicine (Hangzhou, China). Witten informed consent was obtained from all patients. And the experimental protocols for animals were approved by the Ethical Committee for Animal Studies at Zhejiang University.

Consent for publication

Not applicable.

\section{Competing interests}

The authors declare that they have no competing interests.

\section{Author details}

'Key Laboratory of Respiratory Disease of Zhejiang Province, Department of Respiratory and Critical Care Medicine, Second Affiliated Hospital of Zhejiang University School of Medicine, Hangzhou 310009, Zhejiang, China.

${ }^{2}$ Tuberculosis Diagnosis and Treatment Center, Affiliated Hangzhou Chest Hospital, Zhejiang University School of Medicine, Hangzhou 31000, Zhejiang, China. ${ }^{3}$ Linping Campus, The Second Affiliated Hospital of Zhejiang University School of Medicine, Hangzhou 311100, China. ${ }^{4}$ Zhejiang University-University of Edinburgh Institute (ZJU-UoE Institute), Zhejiang University School of Medicine, International Campus, Zhejiang University, Haining 314400, China.

Received: 4 November 2021 Accepted: 6 February 2022

Published online: 12 February 2022

\section{References}

1. The Global Initiative for Chronic Obstructive Lung Disease (GOLD). Global Strategy for the Diagnosis, Management, and Prevention of Chronic Obstructive Pulmonary Disease (2020 REPORT). 2020.

2. Celli BR, Wedzicha JA. Update on clinical aspects of chronic obstructive pulmonary disease. N Engl J Med. 2019;381:1257-66.

3. Wang C, Xu J, Yang L, Xu Y, Zhang X, Bai C, Kang J, Ran P, Shen H, Wen $F$, et al. Prevalence and risk factors of chronic obstructive pulmonary disease in China (the China Pulmonary Health [CPH] study): a national cross-sectional study. Lancet (London, England). 2018;391:1706-17. 
4. Wang Z, Gerstein M, Snyder M. RNA-Seq: a revolutionary tool for transcriptomics. Nat Rev Genet. 2009;10:57-63.

5. Vogelmeier CF, Criner GJ, Martinez FJ, Anzueto A, Agusti A. Global strategy for the diagnosis, management, and prevention of chronic obstructive lung disease 2017 report. Am J Respir Crit Care Med. 2017;53:557.

6. Zhou JS, Li ZY, XU XC, Zhao Y, Wang Y, Chen HP, Zhang M, Wu YF, Lai TW, Di $\mathrm{CH}$, et al. Cigarette smoke-initiated autoimmunity facilitates sensitisation to elastin-induced COPD-like pathologies in mice. Eur Respir J. 2020; 56.

7. Hussain M, Xu C, Lu M, Wu X, Tang L, Wu X. Wnt/beta-catenin signaling links embryonic lung development and asthmatic airway remodeling. Biochim Biophys Acta Mol Basis Dis. 2017;1863:3226-42.

8. Skronska-Wasek W, Mutze K, Baarsma HA, Bracke KR, Alsafadi HN, Lehmann M, Costa R, Stornaiuolo M, Novellino E, Brusselle GG, et al. Reduced frizzled receptor 4 expression prevents WNT/ $\beta$-catenin-driven alveolar lung repair in chronic obstructive pulmonary disease. Am J Respir Crit Care Med. 2017;196:172-85.

9. Kneidinger N, Yildirim AO, Callegari J, Takenaka S, Stein MM, Dumitrascu R, Bohla A, Bracke KR, Morty RE, Brusselle GG, et al. Activation of the WNT/ beta-catenin pathway attenuates experimental emphysema. Am J Respir Crit Care Med. 2011:183:723-33.

10. Uhl FE, Vierkotten S, Wagner DE, Burgstaller G, Costa R, Koch I, Lindner M, Meiners S, Eickelberg O, Konigshoff M. Preclinical validation and imaging of Wnt-induced repair in human 3D lung tissue cultures. Eur Respir J. 2015:46:1150-66.

11. Gordon MD, Nusse R. Wnt signaling: multiple pathways, multiple receptors, and multiple transcription factors. J Biol Chem. 2006;281:22429-33.

12. Kim SY, Lee JH, Huh JW, Ro JY, Oh YM, Lee SD, An S, Lee YS. Cigarette smoke induces Akt protein degradation by the ubiquitin-proteasome system. J Biol Chem. 2011;286:31932-43.

13. Renda T, Baraldo S, Pelaia G, Bazzan E, Turato G, Papi A, Maestrelli P, Maselli $\mathrm{R}$, Vatrella A, Fabbri LM, et al. Increased activation of p38 MAPK in COPD. Eur Respir J. 2008;31:62-9.

14. Zuo Q, Wang Y, Yang D, Guo S, Li X, Dong J, Wan C, Shen Y, Wen F. Identification of hub genes and key pathways in the emphysema phenotype of COPD. Aging (Albany NY). 2021;12:5120.

15. Conesa A, Madrigal P, Tarazona S, Gomez-Cabrero D, Cervera A, McPherson A, Szczesniak MW, Gaffney DJ, Elo LL, Zhang X, Mortazavi A. A survey of best practices for RNA-seq data analysis. Genome Biol. 2016;17:13.

16. Liu Y, Zhou J, White KP. RNA-seq differential expression studies: more sequence or more replication? Bioinformatics. 2014;30:301-4.

17. Pirozzi F, Ren K, Murabito A, Ghigo A. PI3K signaling in chronic obstructive pulmonary disease: mechanisms, targets, and therapy. Curr Med Chem. 2019;26:2791-800.

18. Wang Z, Li R, Zhong R. Extracellular matrix promotes proliferation, migration and adhesion of airway smooth muscle cells in a rat model of chronic obstructive pulmonary disease via upregulation of the PI3K/AKT signaling pathway. Mol Med Rep. 2018;18:3143-52.

19. Tudhope SJ, Finney-Hayward TK, Nicholson AG, Mayer RJ, Barnette MS, Barnes PJ, Donnelly LE. Different mitogen-activated protein kinasedependent cytokine responses in cells of the monocyte lineage. J Pharmacol Exp Ther. 2008;324:306-12.

20. MacNee W, Allan RJ, Jones I, De Salvo MC, Tan LF. Efficacy and safety of the oral p38 inhibitor PH-797804 in chronic obstructive pulmonary disease: a randomised clinical trial. Thorax. 2013;68:738-45.

21. Skronska-Wasek W, Gosens R, Königshoff M, Baarsma HA. WNT receptor signalling in lung physiology and pathology. Pharmacol Ther. 2018;187:150-66.

22. MacDonald BT, He X. Frizzled and LRP5/6 receptors for Wnt/beta-catenin signaling. Cold Spring Harb Perspect Biol. 2012; 4.

23. Nusse R, Clevers H. Wnt/beta-catenin signaling, disease, and emerging therapeutic modalities. Cell. 2017;169:985-99.

24. Wu M, Lai T, Jing D, Yang S, Shen H. Epithelium-derived IL 17A promotes cigarette smoke-induced inflammation and mucus hyperproduction. Am J Respir Cell Mol Biol. 2021;65:581.

25. Huang HQ, Li N, Li DY, Jing D, Chen ZH. Autophagy promotes cigarette smoke-initiated and elastin-driven bronchitis-like airway inflammation in mice. Front Immunol. 2021; 12.

26. Suo T, Chen GZ, Huang Y, Zhao KC, Wang T, Hu K. miRNA-1246 suppresses acute lung injury-induced inflammation and apoptosis via the NFkappaB and Wnt/beta-catenin signal pathways. Biomed Pharmacother. 2018;108:783-91.
27. Cheng J, Yang J, Xue K, Zhao Y, Zhao C, Li S, Wang Z. Desmoglein 3 silencing inhibits inflammation and goblet cell mucin secretion in a mouse model of chronic rhinosinusitis via disruption of the Wnt/beta-catenin signaling pathway. Inflammation. 2019;42:1370-82.

28. Sharma A, Yang WL, Ochani M, Wang P. Mitigation of sepsis-induced inflammatory responses and organ injury through targeting Wnt/betacatenin signaling. Sci Rep. 2017;7:9235.

29. Mao T, He C, Wu H, Yang B, Li X. Silencing IncRNA HOTAIR declines synovial inflammation and synoviocyte proliferation and promotes synoviocyte apoptosis in osteoarthritis rats by inhibiting Wnt/beta-catenin signaling pathway. Cell Cycle. 2019;18:3189-205.

30. Cui W, Zhang Z, Zhang P, Qu J, Zheng C, Mo X, Zhou W, Xu L, Yao H, Gao J. Nrf2 attenuates inflammatory response in COPD/emphysema: crosstalk with Wnt3a/beta-catenin and AMPK pathways. J Cell Mol Med. 2018;22:3514-25.

\section{Publisher's Note}

Springer Nature remains neutral with regard to jurisdictional claims in published maps and institutional affiliations.

Ready to submit your research? Choose BMC and benefit from:

- fast, convenient online submission

- thorough peer review by experienced researchers in your field

- rapid publication on acceptance

- support for research data, including large and complex data types

- gold Open Access which fosters wider collaboration and increased citations

- maximum visibility for your research: over $100 \mathrm{M}$ website views per year

At BMC, research is always in progress.

Learn more biomedcentral.com/submissions 